\title{
Binge Eating Disorder, Depression and Anxiety, and Weight Gain and Increased BMI After Five Years of Bariatric Surgery
}

\author{
Heitor Bernardes Pereira Delfino \\ USP FMRP: Universidade de Sao Paulo Faculdade de Medicina de Ribeirao Preto \\ Marcela Augusta Souza Pinhel \\ USP FMRP: Universidade de Sao Paulo Faculdade de Medicina de Ribeirao Preto
}

Flávia Campos Ferreira

USP FMRP: Universidade de Sao Paulo Faculdade de Medicina de Ribeirao Preto

Carolina Ferreira Nicoletti

USP FMRP: Universidade de Sao Paulo Faculdade de Medicina de Ribeirao Preto

Sofia Teixeira Prates Oliveira

USP FMRP: Universidade de Sao Paulo Faculdade de Medicina de Ribeirao Preto

Lidia Barbieri Belrmino Baumgartner

USP FMRP: Universidade de Sao Paulo Faculdade de Medicina de Ribeirao Preto

Caroline Rossi Welendorf

USP FMRP: Universidade de Sao Paulo Faculdade de Medicina de Ribeirao Preto

Carolina Hunger Malek-Zadeh

USP FMRP: Universidade de Sao Paulo Faculdade de Medicina de Ribeirao Preto

Wilson Salgado Junior

USP FMRP: Universidade de Sao Paulo Faculdade de Medicina de Ribeirao Preto

Carla Barbosa Nonino ( $\square$ carla@fmrp.usp.br)

USP FMRP: Universidade de Sao Paulo Faculdade de Medicina de Ribeirao Preto

https://orcid.org/0000-0001-8559-0772

\section{Research Article}

Keywords: binge eating disorder, obesity, bariatric surgery, anxiety, depression.

Posted Date: October 26th, 2021

DOI: https://doi.org/10.21203/rs.3.rs-999292/v1

License: (9) This work is licensed under a Creative Commons Attribution 4.0 International License. Read Full License 


\section{Abstract}

Objectives

Analyze the influence of Binge Eating Disorder (BED) and symptoms of depression and anxiety on anthropometric and body composition changes over five years after bariatric surgery in patients with obesity.

Methods

Evaluation of 118 individuals undergoing bariatric surgery, divided into two groups: Group 1: individuals with BED; Group 2: individuals without BED. The individuals were submitted to anthropometric and body composition evaluation, and analysis of the presence of BED, depression, and anxiety according to the DSM-V and using validated questionnaires. The Kolmogorovi-Smirnov, $t-$ test, Fisher's, chi-square, and ANOVA were used for statistical analysis.

Results

The groups with BED ( $=61,51,7 \%)$ and without BED (N=57,48,3\%) did not differ from each other for all sociodemographic assessed variables $(p>0.05)$ and had similar changes in waist circumference and body composition over five years after bariatric surgery $(p>0.05)$. On the other hand, only patients with BED had severe depression $(13,11 \%, p=0.0079)$ and had a higher frequency of moderate $(22.95 \%, p=0.0022)$ and severe $(14.75 \%, p=0.0022)$ anxiety in the preoperative period of bariatric surgery. In addition, only the group with BED had increased weight and increased BMI in the fifth year after bariatric surgery $(p<0.05)$.

Conclusion

Patients with BED had more intense symptoms of depression and anxiety, and this disorder may reappear in the postoperative period of bariatric surgery and contribute to weight gain and an increase in BMI.

Level of evidence: III (evidence obtained from case-control analytic study).

\section{Highlights (Optional)}

- Patients with obesity and binge eating disorder have more intense symptoms of depression and anxiety;

- Patients who presented binge eating disorder in the preoperative period of bariatric surgery have greater weight gain and increased BMI in the late postoperative period;

- Binge eating disorder is common in obese patients, candidates for bariatric surgery.

\section{What Is Already Known On This Subject?}

BED may reappear in the postoperative period of bariatric surgery and can contribute to weight gain and increased BMI, but the results are not consistent across studies, there is no association with anxiety and depression together, and a variety of methodological aspects have been identified.

\section{What this study adds?}

This study adds that patients who had BED in the preoperative period of bariatric surgery also had more intense symptoms of depression and anxiety, and had greater weight regain in the late postoperative period.

\section{Introduction}

Obesity is a complex disease with a multifactorial etiology considered one of the most serious public health problems worldwide [1]. Currently, more than a third of the world's population is overweight and it is estimated that by 2030 , around $38 \%$ of the world's adult population will be overweight and $20 \%$ obese [2-3]. Obesity is associated with Binge Eating Disorder (BED) and some studies show that the prevalence of BED in obese individuals ranges from 3.3 to 5.5\% [4]. In addition, individuals with obesity and BED have higher 
food intake, higher risk of developing diseases associated with obesity, lower quality of life and higher risk of developing psychiatric disorders, when compared to individuals with obesity without BED [5].

BED, according to Diagnostic and Statistical Manual of Mental Disorders (DSM-V), is an eating disorder characterized by recurrent episodes of binge eating in the absence of appropriate compensatory behaviors (such as purging, excessive exercise, fasting or use of laxatives) [6], and has a prevalence between $6 \%$ and $69 \%$ in patients undergoing bariatric surgery [7-8]. The causes of BED are wide and involve psychological, genetic, biological and environmental factors [8-9].

BED patients tend to have difficulties with emotional regulation and these difficulties may be related to psychological factors such as depression and anxiety, leading to changes in food intake [10]. The literature also suggests that eating problems, such as binge eating, and psychological factors, such as depression and anxiety, can influence weight loss and maintenance after bariatric surgery [11-13]. However, the results are not consistent across studies and a variety of methodological aspects have been identified [14].

It is described in the literature that the maximum weight loss occurs in the first two years after bariatric surgery, this value being, on average, $37.4 \%$ of the preoperative weight, and that after this period it is common for patients to return to gain weight, and after 5 years of maximum weight lost, $43.6 \%$ regained 5 points of body mass index (BMI) and $67.3 \%$ regained $20 \%$ of maximum weight lost [15]. In this context, the objective of the present study was to analyze the influence of BED and symptoms of depression and anxiety on anthropometric and body composition changes over five years after bariatric surgery in patients with obesity.

\section{Materials And Methods}

Were evaluated 118 individuals aged 18 to 65 years, of mixed race, of both genders, with grade III obesity $\left(\mathrm{BMI} \geq 35 \mathrm{~kg} / \mathrm{m}^{2}\right)$, who underwent bariatric surgery. The individuals were monitored by the Bariatric Surgery Outpatient Clinic of the Clinical Hospital of the Ribeirao Preto Medical School (HCFMRP) and were divided into two groups: Group 1 patients with BED; Group 2 patients without BED. The study was approved by the Research Ethics Committee of the Research Ethics Committee of the Ribeirao Preto Medical School of the University of Sao Paulo (Process 14375/2018), and all participants signed the Informed Consent Form (ICF). Patients under 18 or over 65 with a history of liver disease were excluded from the study; anticoagulated or with coagulation disorders; pregnant women; severe malnourished, anemic, chronic alcohol users or drug users; with a history of recent neoplasia; reoperated or with immediate or late postoperative complications.

Anthropometric and body composition measurements (Height $(\mathrm{H})$, body weight $(\mathrm{W})$, body mass index (BMI), lean mass (LM) and fat mass (FM) were performed at preoperative and over five years after surgery, according to the last care of each patient. The Binge Eating Scale (BES) [16], Beck Depression Inventory (BDI) [17] and Beck Anxiety Inventory (BAI) [18] were applied at preoperative.

\section{Anthropometric and body composition assessment}

For anthropometric assessment, the following indicators were used: weight, height, Body Max Index (BMI) and weight regain (\%). The patients were weighed on a Filizola ${ }^{\circledR}$ digital scale, platform type, with a capacity of $300 \mathrm{~kg}$ and precision of $0.2 \mathrm{~kg}$. To measure height, a vertical nail with a $0.5 \mathrm{~cm}$ graduation was used. The BMI was obtained using the formula: Body Max Index = Weight / Height $^{2}\left(\mathrm{BMI}=\mathrm{W} / \mathrm{H}^{2}\right)$, for the three weighing periods (preoperative [W1], a year and a half after surgery [W2] and 5 years after surgery [W3]); to calculate the percentage of weight regain (WR), the formula WR $=100 \times(5$ years after surgery - a year and a half after surgery) / (preoperative - a year and a half after surgery); to calculate the ideal weight (IW), that is, BMI $=25 \mathrm{~kg} / \mathrm{m}^{2}, \mathrm{IW}=25 \times$ $\mathrm{H}^{2}$; to calculate the current excess weight (EW), the formula EW = W3 - IW. The measurement of waist circumference (WC) was obtained by passing an inextensible measuring tape, with a graduation of $0.1 \mathrm{~mm}$, in the largest circumference between the last rib and the iliac crest. The values stipulated by the World Health Organization (WHO) were used as references: $\leq 80 \mathrm{~cm}$ for women and $\leq 94 \mathrm{~cm}$ for men [19].

To analyze the body composition, the Bioelectrical Impedance device, model Quantum BIA $101 \mathrm{Q}-$ RJL System was used. The examination was performed after twelve hours of fasting, with an empty urinary bladder and with the patient lying down with legs apart and arms in parallel, away from the body. According to the technical description, two adhesive electrodes were placed on the hand (one on the dorsal surface of the right wrist between the ulnar and radius bones and the other on the third metacarpal) and two on the foot (one on the anterior surface of the right ankle, between the portions bones and one on the dorsal surface of the third metacarpal) of the individual. A low-amplitude electrical current (between 500 and $800 \mathrm{~A}$ ) and with a frequency of $50 \mathrm{kHz}$ was 
applied to the distal electrodes of the hand and foot. The resistance and reactance values were placed in special formulas for analyzing the body composition of obese individuals, thus obtaining the lean mass (LM) values. To obtain the values of body fat (FM), the amount of LM (kg) was subtracted from the total weight $(\mathrm{kg})$.

\section{Psychiatric evaluation}

The analysis of the presence of BED, depression and anxiety was performed by trained interviewers, according to the DSM-V [6] criteria and through the application of validated questionnaires [16, 17-18].

\section{Binge Eating Scale (BES)}

The BES is a self-administered questionnaire developed by Gormally et al. [16] and is considered a valid BED tracker for candidates for bariatric surgery [20]. It consists of a list of 16 items and 62 statements, from which the individual must select the one that best represents each item. Each statement corresponds to a score from 0 to 3 and ranges from the absence (" 0 ") to the maximum severity (" 3 ") of binge eating. The BES score correction grid was used for the distribution of patients into the studied groups (with and without BED) according to the total score in the questionnaire. Patients with scores $\leq 17$ were allocated to the group without BED and patients with scores $>17$ points were allocated to the group with BED.

\section{Beck Depression Inventory (BDI)}

The BDI is a 21-item self-report scale developed by Beck et al. [17]. The scale items are rated from 0 to 3 , in ascending order of severity of depression symptoms according to four levels: minimum, mild, moderate, and severe, with the item scores being added together and the total score ranging from 0 to 63 . The intensity of symptoms is analyzed by the total score and the classification of depression is according to the score range, ranging from 0 to 11 points: minimum; 12 to 19 points: mild; from 20 to 35 points: moderate; and from 36 to 63 points: severe.

\section{Beck Anxiety Inventory (BAl)}

Anxiety was measured using the 21 -item self-assessment BAI [18]. The items were rated by the individuals on a four-point scale that reflects: 1 - slightly, 2 - it didn't bother me too much, 3 - moderately: it was very unpleasant, but I could bear it and 4 - severely: difficult to bear. Each item was scored from 0 to 3 according to the severity of anxiety symptoms. Item scores were added together, and the total score (0 to 63) correlated with the level of anxiety, which can be a minimum level, scores from 0 to 10; mild level, scores from 11 to 19; moderate level, scores from 20 to 30; and severe level, scores of 31 and 63.

\section{Statistical Analysis}

The normality of data distribution was verified by the Kolmogorov-Smirnov test, the continuous variables were composed of mean and standard deviation values (all analyzed variables passed the normality test). Differences between groups and periods shown in Table 1 and 2 were analyzed by Student's t-test (all parametric data). Differences between groups and periods shown in Figures 1 and 2 were analyzed by repeated measures ANOVA (all parametric data). The odds ratio (OR) was calculated to check relative risk for BED in selected patients. The analysis of the frequency and classification of depression and anxiety was performed using Fisher's exact test or the chi-square test (Table 3). Statistical significance ( $p$-value) was established at $p<0.05$. The analysis was performed using the Statistical Package for Social Science software (SPSS version 20.0 [Inc. Chicago. IL]).

\section{Results}

Table 1 presents the sociodemographic, anthropometric and body composition data of patients with obesity who underwent bariatric surgery $(N=118)$, distributed in groups with $B E D(N=61,51,7 \%)$ and without $B E D(N=57,48,3 \%)$, within each group there were three periods of analysis (preoperative, postoperative 1 - one and a half year, postoperative 2 - five years). The Student's t-test analysis showed that the groups with and without BED did not differ from each other for all assessed variables ( $p>0.05)$. The female gender prevailed in both groups ( $86,9 \%$ and $77,2 \%$ for the groups with and without BED, respectively), with no statistically significant difference between them $(p=0.065)$ it was shown by Student's t-test. The mean age did not differ between the groups, being $40.1 \pm 9.9$ years for the group with BED and 39.0 \pm 10.5 years for those without BED $(p=0.575)$.

Regarding weight, a significant reduction in this variable was noted when comparing the preoperative periods and after weight loss in the postoperative 1 , for both groups ( $<<0.01$ ), but only the group with BED showed weight regain between postoperative 1 and 2 $(p=0.0002)$. Figure 1 shows the evolution of the patient's weight over the five years after bariatric surgery. Repeated measures ANOVA 
showed that up to the first year and a half after the surgery, both groups presented weight loss $(p<0.001)$, but only the group with BED showed weight regain in the fifth year after surgery $(\mathrm{p}=0.01)$. Regarding BMI, in Table 1 it can be seen, by Student's t-test, that both groups presented a reduction of this parameter in the postoperative $1(p<0.001)$, but only individuals with BED had an increase in BMI between the two postoperative periods presented $(p<0.01)$. In addition, it can be seen in Figure 2 that both groups had a reduction in BMI up to one and a half year after surgery $(p<0.0001)$, but only the group with BED showed an increase in this parameter from the fourth year and a half after the bariatric surgery $(p<0.01)$. On the other hand, according to Table 1 , the percentage of weight regain for the BED group was $18.8 \%$ and $23.3 \%$ for the group without the disorder $(p=0.315)$.

There was no significant difference in comparing weight and BMI for the groups with and without BED in all periods analyzed $(p>0.05)$, showing that the studied groups (with and without BED) are homogeneous for these indicators (Table 1 and Figure 1).

According to Table 1, it can be seen that female subjects with BED had a significant reduction $(p=0.0122)$ in waist circumference between the preoperative and postoperative periods 1 , followed by maintenance until the postoperative $2(p=0.5765)$. Similar results were identified for male patients with BED, who had a significant reduction in waist circumference $(p<0.001)$ between preoperative and postoperative 1 , followed by maintenance until postoperative $2(p=0.8572)$. No significant difference was identified between the means of waist circumference in relation to gender, in the three periods of analysis ( $p=0.9972 ; p>0.9999$ and $p=0.3507)$. In addition, for female subjects without BED, there was a significant reduction in waist circumference $(p=0.0003)$ between preoperative and postoperative 1 , followed by maintenance until postoperative $2(p=0.7691)$. Similar results were identified for male patients without BED, who had a significant reduction in waist circumference $(p=0.0022)$ between preoperative and postoperative 1 , followed by maintenance until postoperative 2 ( $p>0.9999$ ). No significant difference was identified between the means of waist circumference in relation to gender, in the three periods of analysis $(p=0.2089 ; p>0.9999$ and $p>0.9999)$. Regarding the influence of BED on the evolution of the measurement of abdominal circumference in the preoperative period and throughout the postoperative period of female and male individuals, no significant difference was identified between the groups in all periods analyzed $(p>0.05)$.

It is observed in Table 1 that both groups presented a reduction in lean mass in kilograms between preoperative and postoperative period 1 (BED group: $p=0.0116$; group without BED: $p=0.0006$ ), followed by stabilization until postoperative 2 (BED group: $p=0.9995$; group without BED: $p>0.9999)$. On the other hand, in postoperative 1, an increase in the percentage of lean mass was observed in both groups (BED group: $p<0.0001$; group without BED: $p=0.0292$ ), followed by stabilization until the postoperative 2 (BED group: $p>0.9999$; group without BED: $p>0.9999)$. There was no significant difference in lean mass in kilograms and in percentage between the groups with and without $B E D$, in all periods analyzed $(p>0.05)$. In addition, it was identified that both groups presented a reduction in fat mass in kilograms and in percentage between preoperative and postoperative period 1 (BED group: $p=0.0008$ and $p<0.0001$; group without BED: $p<0.0001$ and $p=0.0456$, respectively), followed by stabilization until postoperative 2 (BED group: $p=0.626$ and $p=0.9986$; group without BED: $p>0.9999$ and $p=0.9795)$. There was no significant difference in fat mass in kilograms and in percentage between the groups with and without BED, in all periods evaluated $(p>0.05)$.

As shown in Table 2, it was observed that the group with BED had a higher mean score in the assessment of symptoms of depression using the Beck Depression Inventory (BDI), in the preoperative, than the group without $B E D(p=0.0082$. For this analysis, the BED group was classified as having mild depression and the group without BED as minimal depression. Furthermore, it was also observed that the group with BED had a higher mean score in the assessment of anxiety symptoms using the Beck Anxiety Inventory (BAI) than the group without BED ( $<<0.0001)$. Based on the identified results, the group with BED was classified as having mild anxiety and the group without BED with minimal anxiety (Table 2).

When analyzing the classification of depression individually, it can be seen in Figure 3 that while minimal and mild depression were more frequent in the group without BED ( $56.1 \%$ and $26.3 \%$, respectively), moderate and severe depression were more frequent in the BED group (31.2\% and $13.1 \%$, respectively). Furthermore, it can be seen in Table 3 that patients with or without BED did not present significant difference for minimal, mild and moderate depression ( $p>0.05)$, however, only patients with BED had severe depression in the preoperative period $(p=0.0079)$. In relation to the classification of anxiety and frequency in the preoperative period, as shown in Table 3 and Figure 4, it was observed that the group without BED had a higher frequency of individuals with minimal anxiety (80.7\%, $p=0.0475)$, but, on the other hand, it was identified that individuals with BED had a higher frequency of moderate $(23.0 \%, p=0.0022)$ and severe $(14.8 \%, \mathrm{p}=0.0022)$ anxiety in the preoperative period of bariatric surgery.

\section{Discussion}


In this study, we found that obese patients with BED had higher levels of depression and anxiety in the preoperative period of bariatric surgery, and increased weight and BMI in the late postoperative period of bariatric surgery. The literature suggests that in pre-bariatric surgery patients, the prevalence of BED may vary between 6 and $69 \%$ [7-8], being $6 \%$ low and $69 \%$ high. Our finding of $51.7 \%$ is closer to the upper end of this spectrum.

In line with other studies, age, gender, and BMI were not different between the groups [12, 21-22], and both the group with BED and the group without BED had similar changes in waist circumference (WC) and body composition over five years after bariatric surgery (Table 1). Although both groups and both sexes showed a significant reduction in WC between the preoperative and postoperative periods, the values remained above those stipulated by the WHO [19], conferring a greater cardiometabolic risk in this population [23].

Weight regain is a complex, multifactorial mechanism, and is related to several factors such as lifestyle, mental health, hormones, surgical factors, inappropriate nutrition [24], ethanol consumption [25], lack of physical activity [26]. A cohort study carried out in 1406 patients showed that the maximum weight loss occurs in the first two years after bariatric surgery, this value being, on average, $37.4 \%$ of the pre-surgery weight. After this period, it is common for patients to regain weight, and after 5 years of the maximum weight lost, $43.6 \%$ recovered 5 points of $\mathrm{BMI}$ and $67.3 \%$ recovered $20 \%$ of the maximum weight lost [15]. In our sample, although the regained weight between the groups did not show a significant difference (Table 1), it was observed that only the group of patients with BED had increased weight and BMI in the fifth year after bariatric surgery $(p<0.05)$, suggesting the recurrence of this disorder at a later period (Figures 1 and 2).

Another relevant factor for weight recurrence in the postoperative period is psychiatric disorders, such as depression and anxiety. Some studies have shown a higher prevalence of these disorders among obese patients who are candidates for bariatric surgery [27-28]. In this sample, all patients had some level of depression and anxiety preoperatively (Table 3), but patients with BED had a higher prevalence of moderate and severe types of these disorders (Figures 3 and 4). It was observed that the BED group had a higher mean score (Table 2) preoperatively in the assessment of depression symptoms using the Beck Depression Inventory (BDI), than the group without BED $(p<0.05)$, and higher frequency (Figure 3$)$ of severe depression $(13.11 \%)$. In addition, it was also observed that the group with BED preoperatively, had a higher mean score (Table 2) in the assessment of anxiety symptoms using the Beck Anxiety Inventory (BAI) than the group without BED ( $<<0.05)$, and higher frequency (Figure 4) of moderate $(22.95 \%)$ and severe $(14.75 \%)$ anxiety.The results identified on the assessment of symptoms of depression and anxiety in the study population are in agreement with the literature, and studies show that individuals with obesity and BED have higher rates of depression and anxiety than individuals with obesity and without BED [8, 29-30]. In addition, a study by Peterson et al. [31] identified in a series of 32 women with grade I obesity that patients with BED $(n=15)$ had significantly more symptoms of depression (10.1 versus $4.8, p=0.005)$ and anxiety ( 8.5 versus $2.7, p=0.003)$, than normal-weight patients $(n=17)$, demonstrating that normal-weight and non-BED individuals have a lower frequency of these symptoms.

The strength of this study is that it was possible to follow the participants for a long period of time, while most published studies with BED in the preoperative period do not follow the patients throughout the postoperative period or follow up within 2 years after surgery. In addition, it was possible to associate BED with higher levels of depression and anxiety in the preoperative period and to monitor anthropometric and body composition variables in obese patients during five years after bariatric surgery.

However, our study has a few limitations. One of them is related to the sample size, but it is a problem reported in the literature, as many patients who undergo bariatric surgery lose follow-up in the first postoperative years. Several studies have shown increasingly lower rates of adherence to scheduled postoperative appointments, with $50 \%$ in the first year, $30 \%$ in 2 years and $<10 \%$ in 10 years [32-35]. Another limitation is the no reavaluation of BED, depression and anxiety throughout the postoperative period. However, in addition to BED being common in preoperatively obese patients, this eating disorder can reappear in the postoperative period and contribute to reducing the effects of bariatric surgery [36]. Despite the physical limitations of surgery on stomach capacity and food intolerances developed during the postoperative period, binge eating is not always eliminated. In the short term, binge eating episodes can decrease or even be eliminated, however, some long-term studies report a considerable amount of binge eating episodes after bariatric surgery, especially if they were already present before surgery [37-38].

On the other hand, the regained weight and increased BMI identified in patients with BED in the late postoperative period (Figures 1 and 2) suggest the recurrence of this disorder and that it may possibly be associated with symptoms of anxiety and depression (Figure 5). Based on this, additional studies are needed to provide clearer answers about long-term weight maintenance and the influence of BED, depression and anxiety throughout the postoperative period.

Page 6/13 


\section{Conclusion}

In conclusion, patients with obesity and BED had more intense symptoms of depression and anxiety in the preoperative period of bariatric surgery. In addition, patients who were identified with BED in the preoperative period showed weight gain and increased BMI in the late postoperative period of bariatric surgery, suggesting a possible recurrence of this disorder and a possible association with symptoms of depression and anxiety.

\section{Declarations}

\section{Funding}

This research was supported by Sao Paulo Research Foundation (FAPESP) (\#grants numbers: 2018/24069-3, 2018/08784-4 and 2013/12819-4] and National Council for Scientific and Technological Development (CNPq) [\#grant No. 480763/2013-5 and 408292/2018-0].

\section{Conflicts of interest/Competing interests}

The authors declare no conflict of interest. The funders had no role in the design of the study, in the collection, analysis, or interpretation of data, in the writing of the manuscript, or in the decision to publish the results.

\section{Ethical approval and Informed consent}

The study was approved by the Research Ethics Committee of the Research Ethics Committee of the Ribeirao Preto Medical School of the University of Sao Paulo (Process 14375/2018), and all participants signed the Informed Consent Form (ICF).

\section{Availability of data and material}

Anonymized data and analysis are available from the corresponding author on reasonable request.

\section{References}

1. Hruby A, Hu FB. (2015) The Epidemiology of Obesity: A Big Picture. Pharmacoeconomics. 33(7):673-89. doi: 10.1007/s40273014-0243-x.

2. Kelly T, Yang W, Chen CS, Reynolds K, He J. (2008) Global burden of obesity in 2005 and projections to 2030. Int J Obes (Lond). 32(9):1431-7. doi: 10.1038/ijo.2008.102.

3. Ng M, Fleming T, Robinson M, Thomson B, Graetz N, Margono C, Mullany EC, Biryukov S, Abbafati C, Abera SF, Abraham JP, AbuRmeileh NM, Achoki T, AlBuhairan FS, Alemu ZA, Alfonso R, Ali MK, Ali R, Guzman NA, et al. (2014) Global, regional, and national prevalence of overweight and obesity in children and adults during 1980-2013: a systematic analysis for the Global Burden of Disease Study 2013. Lancet. 30,384(9945):766-81. doi: 10.1016/S0140-6736(14)60460-8. Epub 2014 May 29. Erratum in: Lancet. 2014 Aug 30,384(9945):746.

4. Cossrow N, Pawaskar M, Witt EA, Ming EE, Victor TW, Herman BK, Wadden TA, Erder MH. (2016) Estimating the Prevalence of Binge Eating Disorder in a Community Sample From the United States: Comparing DSM-IV-TR and DSM-5 Criteria. J Clin Psychiatry. 77(8):e968-74. doi: 10.4088/JCP.15m10059.

5. Agüera Z, Lozano-Madrid M, Mallorquí-Bagué N, Jiménez-Murcia S, Menchón JM, Fernández-Aranda F. (2021) A review of binge eating disorder and obesity. Neuropsychiatr. 35(2):57-67. English. doi: 10.1007/s40211-020-00346-w.

6. American Psychiatric Association, American Psychiatric Association, DSM-5 task force. (2013) Diagnostic and statistical manual of mental disorders: DSM-5. Arlington, Va: American Psychiatric Association.

7. Sansone RA, Schumacher D, Wiederman MW, Routsong-Weichers L. (2008) The prevalence of binge eating disorder and borderline personality symptomatology among gastric surgery patients. Eat Behav. 9(2):197-202. doi:

10.1016/j.eatbeh.2007.08.002.

8. Nonino CB, Barato M, Ferreira FC, Delfino HBP, Noronha NY, Nicoletti CF, Junior WS, Welendorf CR, Souza DRS, Ferreira-Julio MA, Watanabe LM, de Souza Pinhel MA. (2021) DRD2 and BDNF polymorphisms are associated with binge eating disorder in 
patients with weight regain after bariatric surgery. Eat Weight Disord. Sep 3. doi: 10.1007/s40519-021-01290-6.

9. Treasure J, Claudino AM, Zucker N. (2010) Eating disorders. Lancet. 13,375(9714):583-93. doi: 10.1016/S0140-6736(09)617487.

10. Leehr EJ, Krohmer K, Schag K, Dresler T, Zipfel S, Giel KE. (2015) Emotion regulation model in binge eating disorder and obesitya systematic review. Neurosci Biobehav Rev. 49:125-34. doi: 10.1016/j.neubiorev.2014.12.008.

11. Kalarchian MA, Marcus MD, Levine MD, Courcoulas AP, Pilkonis PA, Ringham RM, Soulakova JN, Weissfeld LA, Rofey DL. (2007) Psychiatric disorders among bariatric surgery candidates: relationship to obesity and functional health status. Am J Psychiatry. 164(2):328-34, quiz 374. doi: 10.1176/ajp.2007.164.2.328.

12. Dawes AJ, Maggard-Gibbons M, Maher AR, et al. (2016) Mental Health Conditions Among Patients Seeking and Undergoing Bariatric Surgery: A Meta-analysis. JAMA. 315(2):150-163. doi:10.1001/jama.2015.18118

13. Jones-Corneille LR, Wadden TA, Sarwer DB, et al. (2012) Axis I psychopathology in bariatric surgery candidates with and without binge eating disorder: results of structured clinical interviews. Obes Surg. 22(3):389-397. doi:10.1007/s11695-010-0322-9

14. Sarwer DB, Wadden TA, Fabricatore AN. (2005) Psychosocial and behavioral aspects of bariatric surgery. Obes Res. 13(4):63948. doi: 10.1038/oby.2005.71.

15. King WC, Hinerman AS, Belle SH, Wahed AS, Courcoulas AP. (2018) Comparison of the Performance of Common Measures of Weight Regain After Bariatric Surgery for Association With Clinical Outcomes. JAMA. 16,320(15):1560-1569. doi: 10.1001/jama.2018.14433.

16. Gormally J, Black S, Daston S, Rardin D. (1982) The assessment of binge eating severity among obese persons. Addict Behav. 7(1):47-55. doi: 10.1016/0306-4603(82)90024-7.

17. Beck AT, Ward CH, Mendelson M, Mock J, Erbaugh J. (1961) An inventory for measuring depression. Arch Gen Psychiatry. 4:56171. doi: 10.1001/archpsyc.1961.01710120031004.

18. Beck AT, Epstein N, Brown G, Steer RA. (1988) An inventory for measuring clinical anxiety: psychometric properties. J Consult Clin Psychol. 56(6):893-7. doi: 10.1037//0022-006x.56.6.893.

19. Ross R, Neeland IJ, Yamashita S, Shai I, Seidell J, Magni P, Santos RD, Arsenault B, Cuevas A, Hu FB, Griffin BA, Zambon A, Barter P, Fruchart JC, Eckel RH, Matsuzawa Y, Després JP. (2020) Waist circumference as a vital sign in clinical practice: a Consensus Statement from the IAS and ICCR Working Group on Visceral Obesity. Nat Rev Endocrinol. 16(3):177-189. doi: 10.1038/s41574019-0310-7.

20. Grupski AE, Hood MM, Hall BJ, Azarbad L, Fitzpatrick SL, Corsica JA. (2013) Examining the Binge Eating Scale in screening for binge eating disorder in bariatric surgery candidates. Obes Surg. 23(1):1-6. doi: 10.1007/s11695-011-0537-4.

21. Mitchell JE, King WC, Courcoulas A, Dakin G, Elder K, Engel S, Flum D, Kalarchian M, Khandelwal S, Pender J, Pories W, Wolfe B. (2015) Eating behavior and eating disorders in adults before bariatric surgery. Int J Eat Disord. 48(2):215-22. doi: 10.1002/eat.22275.

22. Cella S, Fei L, D'Amico R, Giardiello C, Allaria A, Cotrufo P. (2019) Binge Eating Disorder and Related Features in Bariatric Surgery Candidates. Open Med (Wars). 14:407-415. Published 2019 Jun 7. doi:10.1515/med-2019-0043

23. Krakauer NY, Krakauer JC. (2018) Untangling Waist Circumference and Hip Circumference from Body Mass Index with a Body Shape Index, Hip Index, and Anthropometric Risk Indicator. Metab Syndr Relat Disord. 16(4):160-165. doi: 10.1089/met.2017.0166.

24. Maleckas A, Gudaitytè R, Petereit R, Venclauskas L, Veličkienè D. (2016) Weight regain after gastric bypass: etiology and treatment options. Gland Surg. 5(6):617-624. doi:10.21037/gs.2016.12.02

25. Acevedo MB, Teran-Garcia M, Bucholz KK, Eagon JC, Bartholow BD, Burd NA, Khan N, Rowitz B, Pepino MY. (2020) Alcohol sensitivity in women after undergoing bariatric surgery: a cross-sectional study. Surg Obes Relat Dis. 16(4):536-544. doi: 10.1016/j.soard.2020.01.014.

26. Kushner RF, Sorensen KW. (2015) Prevention of Weight Regain Following Bariatric Surgery. Curr Obes Rep. 4(2):198-206. doi: 10.1007/s13679-015-0146-y.

27. McGarrity LA, Perry NS, Derbidge CM, Trapp SK, Terrill AL, Smith TW, Ibele AR, MacKenzie JJ. (2019) Associations Between Approach and Avoidance Coping, Psychological Distress, and Disordered Eating Among Candidates for Bariatric Surgery. Obes Surg. 29(11):3596-3604. doi: 10.1007/s11695-019-04038-5. 
28. Gravani S, Matiatou M, Nikolaidis PT, Menenakos E, Zografos CG, Zografos G, Albanopoulos K. (2020) Anxiety and Depression Affect Early Postoperative Pain Dimensions after Bariatric Surgery. J Clin Med. 25,10(1):53. doi: 10.3390/jcm10010053.

29. Grilo CM, White MA, Masheb RM. (2009) DSM-IV psychiatric disorder comorbidity and its correlates in binge eating disorder. Int $J$ Eat Disord. 42(3):228-34. doi: 10.1002/eat.20599.

30. Azarbad L, Corsica J, Hall B, Hood M. (2010) Psychosocial correlates of binge eating in Hispanic, African American, and Caucasian women presenting for bariatric surgery. Eat Behav. 11(2):79-84. doi: 10.1016/j.eatbeh.2009.10.001.

31. Peterson RE, Latendresse SJ, Bartholome LT, Warren CS, Raymond NC. (2012) Binge Eating Disorder Mediates Links between Symptoms of Depression, Anxiety, and Caloric Intake in Overweight and Obese Women. J Obes. 2012:407103. doi: 10.1155/2012/407103.

32. Khorgami Z, Zhang C, Messiah SE, de la Cruz-Muñoz N. (2015) Predictors of Postoperative Aftercare Attrition among Gastric Bypass Patients. Bariatr Surg Pract Patient Care. 1,10(2):79-83. doi: 10.1089/bari.2014.0053.

33. Harper J, Madan AK, Ternovits CA, Tichansky DS. (2007) What happens to patients who do not follow-up after bariatric surgery? Am Surg. 73(2):181-4. PMID: 17305299.

34. Higa K, Ho T, Tercero F, Yunus T, Boone KB. (2011) Laparoscopic Roux-en-Y gastric bypass: 10-year follow-up. Surg Obes Relat Dis. 7(4):516-25. doi: 10.1016/j.soard.2010.10.019.

35. Lujan J, Tuero C, Landecho MF, Moncada R, A Cienfuegos J, Rotellar F, Silva C, Lapuente F, Martínez P, Frühbeck G, Valenti V. (2020) Impact of Routine and Long-Term Follow-Up on Weight Loss after Bariatric Surgery. Obes Surg. 30(11):4293-4299. doi: 10.1007/s11695-020-04788-7.

36. Meany G, Conceição E, Mitchell JE. (2014) Binge eating, binge eating disorder and loss of control eating: effects on weight outcomes after bariatric surgery. Eur Eat Disord Rev. 22(2):87-91. doi: 10.1002/erv.2273.

37. Pekkarinen T, Koskela K, Huikuri K, Mustajoki P. (1994) Long-term Results of Gastroplasty for Morbid Obesity: Binge-Eating as a Predictor of Poor Outcome. Obes Surg. 4(3):248-255. doi: 10.1381/096089294765558467.

38. Kofman MD, Lent MR, Swencionis C. (2010) Maladaptive eating patterns, quality of life, and weight outcomes following gastric bypass: results of an Internet survey. Obesity (Silver Spring). 18(10):1938-43. doi: 10.1038/oby.2010.27.

\section{Tables}

Table 1. Sociodemographic. anthropometric and body composition data of patients with and without binge eating disorder (BED) 


\begin{tabular}{|c|c|c|c|c|c|c|c|}
\hline Variables & With BED & & Withou & BED & & & $\underset{\text { value }}{p}$ \\
\hline & $N=61$ & & $N=57$ & & & & \\
\hline Sociodemographic & $\mathbf{N}$ & $\%$ & $\mathbf{N}$ & & $\%$ & & \\
\hline Female & 53 & 86.9 & 44 & & 77.2 & & 0.065 \\
\hline Male & 8 & 13.1 & 13 & & 22.8 & & \\
\hline Anthropometric & Preoperative & $\begin{array}{l}\text { Postoperative } \\
1\end{array}$ & $\begin{array}{l}\text { Postoperative } \\
2\end{array}$ & Preoperative & $\begin{array}{l}\text { Postoperative } \\
1\end{array}$ & $\begin{array}{l}\text { Postoperative } \\
2\end{array}$ & \\
\hline & $\mathrm{M} \pm \mathrm{SD}$ & $M \pm S D$ & $\mathrm{M} \pm \mathrm{SD}$ & $\mathrm{M} \pm \mathrm{SD}$ & $M \pm S D$ & $\mathrm{M} \pm S D$ & \\
\hline Age (years) & $40.1 \pm 9.9$ & - & - & $39.04 \pm 10.5$ & - & - & 0.575 \\
\hline Weight (kg) & $133.4 \pm 22.94$ & $83.49 \pm 15.45^{\star}$ & $92.57 \pm 16.52^{\star}$ & $132.4 \pm 27.26$ & $86.48 \pm 19.62^{\star}$ & $94.24 \pm 20.75$ & $\#$ \\
\hline Height (m) & $1.63 \pm 0.09$ & - & - & $1.65 \pm 0.09$ & - & - & 0.226 \\
\hline BMI $\left(\mathrm{kg} / \mathrm{m}^{2}\right)$ & $50.98 \pm 7.9$ & $32.08 \pm 5.7^{*}$ & $34.25 \pm 7.21^{*}$ & $50.21 \pm 8.2$ & $32.38 \pm 5.57 *$ & $32.82 \pm 10.55$ & $\#$ \\
\hline Ideal weight $(\mathrm{kg})$ & $66.69 \pm 7.41$ & - & - & $68.3 \pm 7.29$ & - & - & 0.231 \\
\hline Overweight (kg) & $29.52 \pm 21.9$ & - & - & $23.35 \pm 20.1$ & - & - & 0.424 \\
\hline Regain (\%) & $18.84 \pm 23.16$ & - & - & $9.05 \pm 38.73$ & - & - & $0 . .315$ \\
\hline WC-F (cm) & $137.6 \pm 26.98$ & $101.5 \pm 12.35^{\star}$ & $107.1 \pm 10.75$ & $141.1 \pm 15.08$ & $111.5 \pm 13.12^{\star}$ & $102.0 \pm 17.56$ & $\#$ \\
\hline WC-M (cm) & $155.9 \pm 15.98$ & $111.6 \pm 13.21^{*}$ & $119.0 \pm 9.89$ & $155.9 \pm 15.98$ & $111.6 \pm 13.21^{*}$ & $119.0 \pm 9.89$ & $\#$ \\
\hline LM (kg) & $66.93 \pm 16.42$ & $55.38 \pm 10.92 *$ & $56.62 \pm 13.01$ & $70.21 \pm 15.08$ & $55.63 \pm 9.86^{*}$ & $52.2 \pm 6.87$ & $\#$ \\
\hline LM (\%) & $51.14 \pm 8.1$ & $67.74 \pm 10.2^{*}$ & $65.51 \pm 4.61$ & $52.1 \pm 6.88$ & $67.55 \pm 10.27 *$ & $66.63 \pm 13.1$ & $\#$ \\
\hline $\mathrm{FM}(\mathrm{kg})$ & $70.84 \pm 18.86$ & $31.59 \pm 14.67 *$ & $35.87 \pm 12.38$ & $67.85 \pm 15.39$ & $26.34 \pm 13.04^{\star}$ & $27.48 \pm 14.6$ & $\#$ \\
\hline FM (\%) & $51.14 \pm 8.99$ & $33.31 \pm 7.63^{*}$ & $36.59 \pm 4.79$ & $47.58 \pm 7.99$ & $30.56 \pm 10.63^{*}$ & $33.37 \pm 13.1$ & $\#$ \\
\hline
\end{tabular}

T-test; $p$-value $=$ significance level for $p<0.05 ;{ }^{*}<<0.05$ compared to the previous period; Postoperative $1=$ one and a half year after surgery; Postoperative 2 = five years after surgery $M=$ mean; $S D=$ standard deviation; $B M I=$ Body Mass Index; $N=$ number; $W C=$ waist circumference; $L M=$ lean mass; $F M=$ fat mass; $\#$ = values described in the text.

Table 2. Score and mean classification of depression and anxiety symptoms of patients with and without binge eating disorder (BED) in the preoperative period of bariatric surgery

\begin{tabular}{lllllll} 
Variables & BDI & BDI & $p$ value & BAl & BAl & $p$ value \\
& With BED & Without BED & & With BED & Without BED & \\
& $\mathbf{N}=61$ & $\mathbf{N}=57$ & $\mathbf{N}=61$ & $\mathbf{N}=57$ & \\
& $\mathrm{M} \pm \mathrm{SD}$ & $\mathrm{M} \pm \mathrm{SD}$ & & $\mathrm{M} \pm \mathrm{SD}$ & $\mathrm{M} \pm \mathrm{SD}$ & \\
\hline Preoperative & $18.86 \pm 12.92^{\star}$ & $11.56 \pm 7.9$ & 0.0082 & $15.74 \pm 11.02^{\star}$ & $6.64 \pm 5.17$ & $<0.0001$ \\
\hline Avarage rating & Mild & Minimum & & Mild & Minimum &
\end{tabular}


T-test; $p$ value $=$ significance level for $p<0.05 ;{ }^{*} p<0.05$ compared to the group without $B E D ; M=$ mean; $S D=$ standard deviation.

Table 3. Preoperative depression and anxiety classification and frequency in individuals with or without BED

\begin{tabular}{|c|c|c|c|c|c|c|}
\hline \multirow[t]{4}{*}{ Variables } & BDI & BDI & $p$ value & BAl & BAl & $p$ value \\
\hline & With BED & Without BED & $(\mathrm{OR} / \mathrm{Cl})$ & With BED & Without BED & $(\mathrm{OR} / \mathrm{Cl})$ \\
\hline & $N=61$ & $N=57$ & & $N=61$ & $N=57$ & \\
\hline & $\mathbf{N}$ & $\mathbf{N}$ & & $\mathbf{N}$ & $\mathbf{N}$ & \\
\hline \multirow[t]{2}{*}{ Minimum } & 21 & 32 & 0.1439 & 27 & 46 & 0.0475 \\
\hline & & & $(1.63 / 0.84-3.11)$ & & & $(1.82 / 1.01-3.24)$ \\
\hline \multirow[t]{2}{*}{ Mild } & 13 & 15 & 0.6163 & 11 & 10 & 0.9538 \\
\hline & & & $(1.24 / 0.55-2.87)$ & & & $(0.97 / 0.37-2.46)$ \\
\hline \multirow[t]{2}{*}{ Moderate } & 19 & 10 & 0.1806 & 14 & 1 & 0.0022 \\
\hline & & & $(0.56 / 0.24-1.29)$ & & & $(0.07 / 0.007-0.51)$ \\
\hline \multirow[t]{2}{*}{ Severe } & 8 & 0 & 0.0079 & 9 & 0 & 0.005 \\
\hline & & & $(0.00 / 0.00-0.52)$ & & & $(0.00 / 0.00-0.44)$ \\
\hline
\end{tabular}

Fisher's exact test or $\mathrm{X}^{2} ; \mathrm{OR}=$ Odds Ratio; $\mathrm{Cl}=$ Confidence Interval; $\mathrm{p}$ value $=$ significance level for $\mathrm{p}<0.05 ; \mathrm{N}=$ number .

\section{Figures}

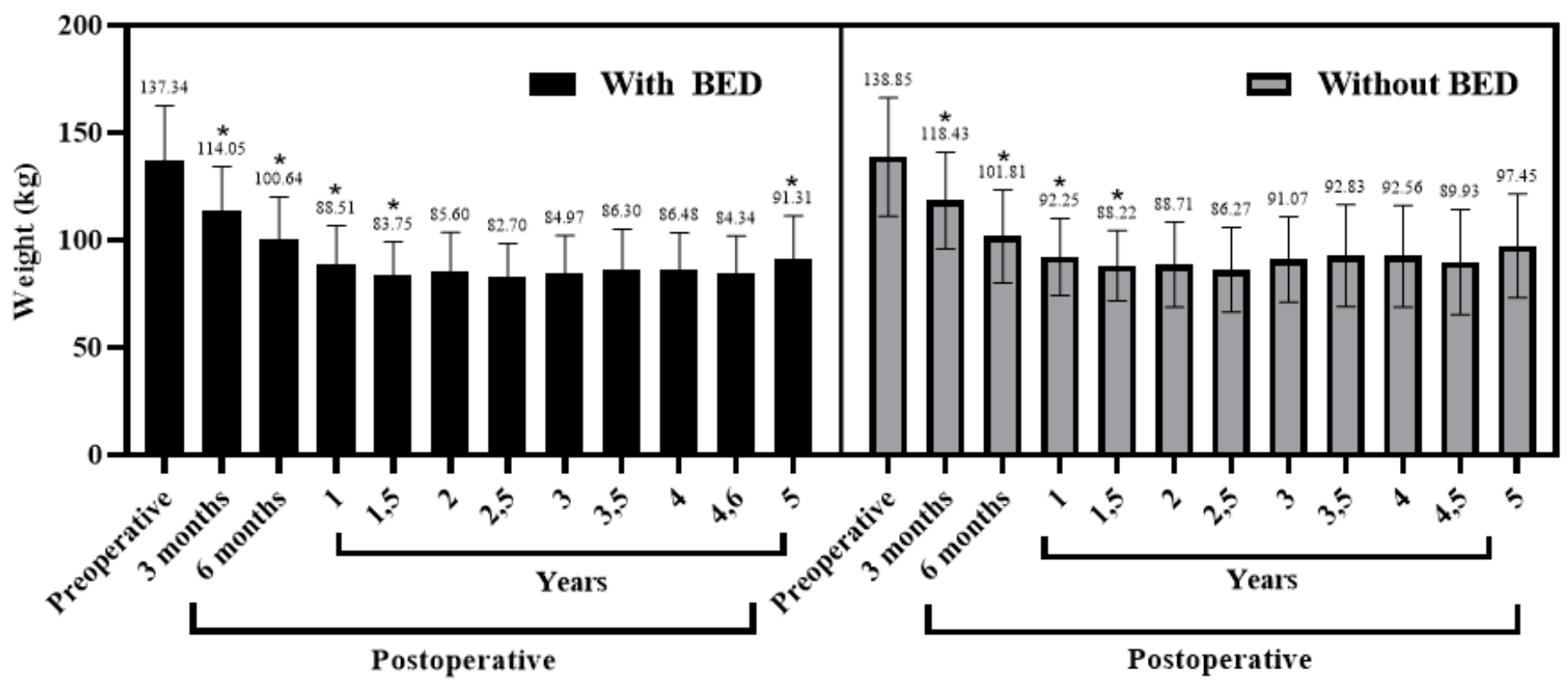

Figure 1

Evolution of weight of patients with or without BED undergoing bariatric surgery over five years ANOVA repeated measures; ${ }^{*} p<0,05$. 


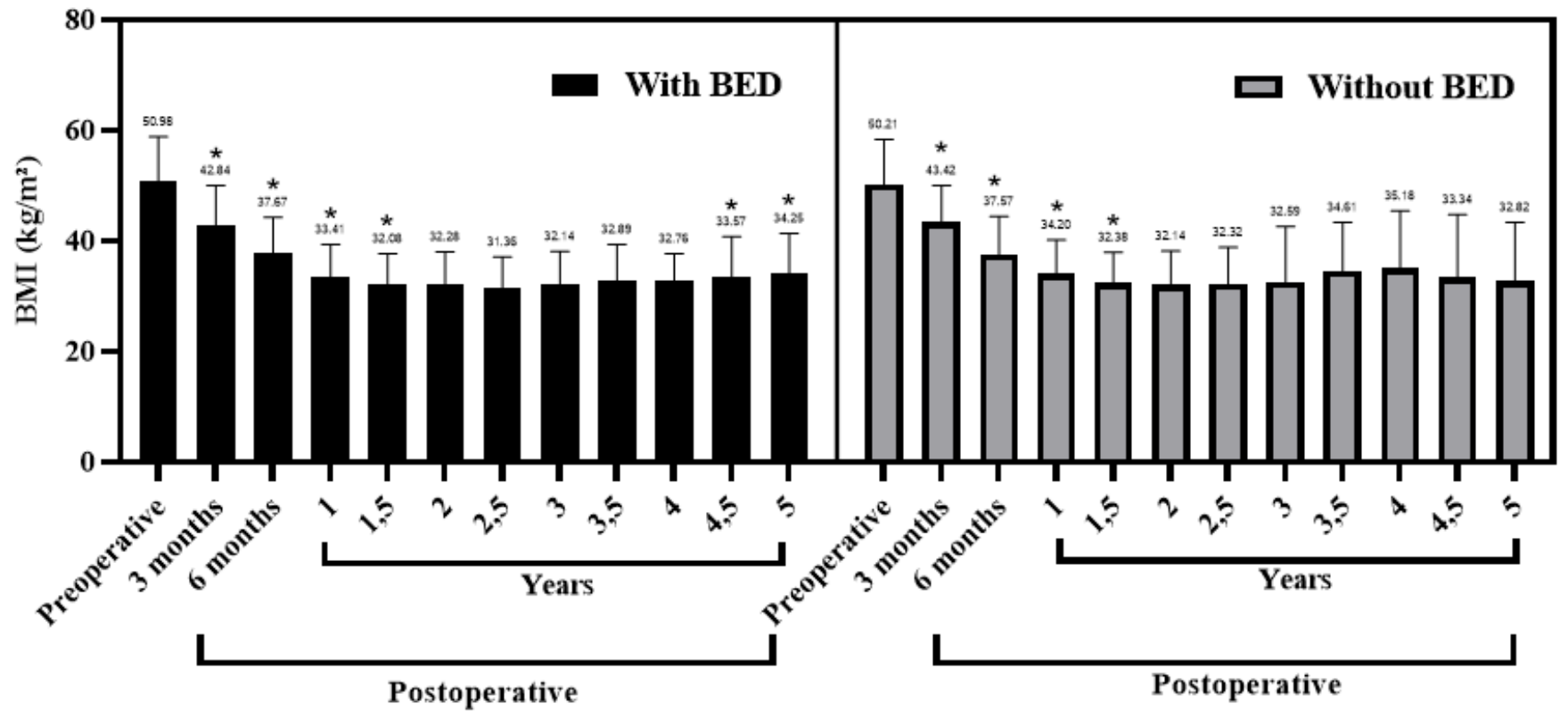

Figure 2

Evolution of BMI of patients with or without BED undergoing bariatric surgery over five years ANOVA repeated measures; $\mathrm{BMI}=$ body mass index; ${ }^{*} \mathrm{p}<0,05$.

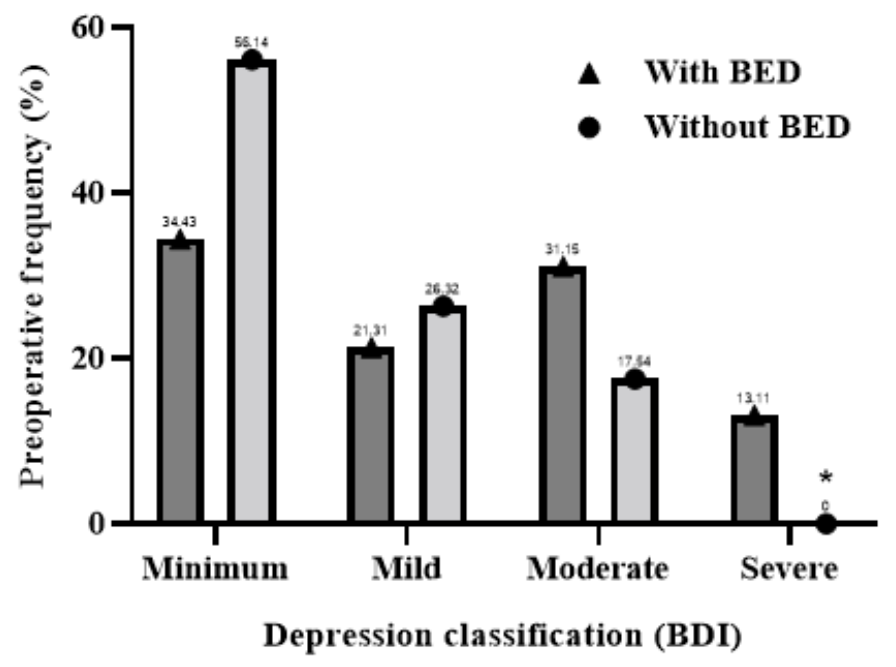

Figure 3

Preoperative depression classification and frequency in individuals with or without BED Fisher's exact test or $\mathrm{X} 2$; * $\mathrm{p}<0.05$ in relation to the group with BED. 


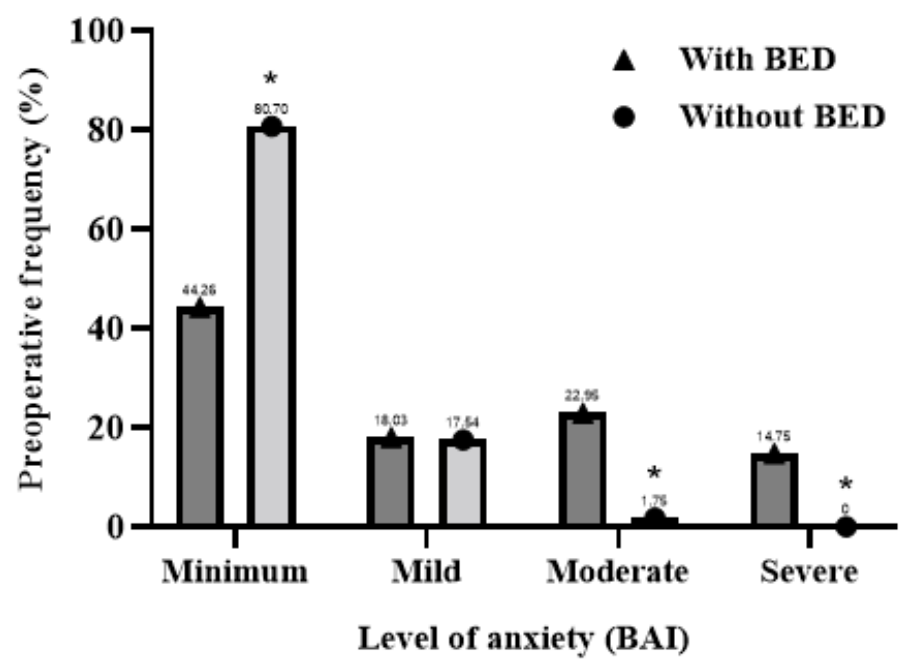

Figure 4

Preoperative anxiety classification and frequency in individuals with or without BED Fisher's exact test or $\mathrm{X} 2$; ${ }^{*} \mathrm{p}<0.05$ in relation to the group with BED. 